\title{
Partial Sequencing of Putative Trypsin cDNAs in Cry1Ac Susceptible and Resistant Strains of Helicoverpa armigera (Hubner)
}

\author{
K. M. Sharma*, A. A. Bharose and R. N. Dhawale
}

Vilasrao Deshmukh College of Agricultural Biotechnology, Latur, VNMKV, Parbhani, India

*Corresponding author

\section{A B S T R A C T}

Keywords

Bacillus

thuringiensis,

Helicoverpa

armigera, Cry1 Ac

resistant, Cry1 Ac

susceptible, trypsin cDNAs

Article Info

Accepted:

12 April 2021

Available Online:

10 May 2021
Insect bioassays were carried out of field strain of Helicoverpa armigera that survived on $\mathrm{Bt}$ cotton. These insects were reared on Cry1Ac incorporated diet that served as the initial culture for selection of resistance. Based on the partial sequences of putative trypsin mRNA of Helicoverpa armigera (accession no. AFO45138) trypsin specific primers were designed. A part of trypsin specific gene that includes the catalytic site $\left(\mathrm{ASP}_{102}\right.$ and $\left.\mathrm{Ser}_{195}\right)$ was sequenced in Cry1Ac susceptible and resistant strains of Helicoverpa armigera. Sequencing demonstrates four amino acid changes in susceptible and resistant strains. Threonine, aspartic acid, serine and histidine at 180, 185, 186 and 192 amino acid positions were substituted with alanine, valine, glycine and glutimic acid respectively in resistant strain.

\section{Introduction}

Bacillus thuringiensis $\delta$-endotoxins $(\mathrm{Bt})$ are an alternative to traditional chemical agents for managing many economically important insects. The mode of action of $\delta$-endotoxins involves proteolytic activation, binding of toxin to receptors, pore formation, leading to ionic imbalance, cessation of feeding, septicaemia, and eventual death (1). Proteinases are involved in solubilizing and activating Bt protoxins, which allows for the binding of toxins to target tissues. Recent evidence indicates that altered gut proteinases may enable some insects to adapt to Bt toxins. Oppert et al., $(2,3,4)$ repoted that a strain of $P$. interpunctella resistant to $\mathrm{Bt}$ subspecies entomocidus has low soluble gut proteinase and $\mathrm{Bt}$ protoxin-hydrolyzing activities when compared with the parent-susceptible strain and a strain resistant to Bt subspecies kurstaki. In the tobacco budworm, Heliothis virescens, not only was a Bt- resistant strain unable to activate the protoxin fully, but also degradation of the active toxin was accelerated by gut proteinases (5). 
Helicoverpa armigera (Amercan boll worm) is polyphagous pest with a wide range of 181 host species in India including cotton, maize, chickpea, pigeonpea, tomato sunflower and several vegetable crops (6). $H$. armigera could adopt Bt toxins within few generations in the laboratory (7). Proteases responsible for protoxin activation are mentioned as being of the trypsin or chymotrypsin like enzyme, in several insect species (8). All the trypsin-like cDNAs contain the catalytic triad His 57 $\mathrm{ASP}_{102}$ and Ser ${ }_{195}$. $\mathrm{ASP}_{189}$ residue determines the trypsin-like specificity for basic amino acids (9). The present study was targeted to get the preliminary idea about the sequence differences (s) of the trypsin-like enzymes cDNAs, which covers the catalytic sites $\mathrm{ASP}_{102}, \mathrm{Ser}_{195}$ of the susceptible and resistants strins of Helicoverpa armigera to Cry1Ac toxin.

\section{Materials and Methods}

The investigations were carried out at Department of Plant Biotechnology, Vilasrao Deshmukh College of Agricultural Biotechnology, Latur (India) in 2015, to study the nucleotide differences of trypsin cDNAs of Cry1Ac susceptible and resistant strains of Helicoverpa armigera (Hubner).

\section{Insects}

Field collected strains of Helicoverpa armigera were maintained in the laboratory without selection pressure. A laboratory selected Cry1Ac resistant strain was generated through repeated selection on a diet of Cry1Ac toxin. The Cotton Research Station, Nanded (VNMKV, Parbhani) kindly provided susceptible strain of H.armigera.

\section{Chemicals and Bt toxins}

The chemicals and reagents for agarose gel electrophoresis were purchased from Sigma
Chemical. Taq polymerase, dNTPs were purchased from Bangalore Genei and primer used for sequencing was purchased from IDT, USA. PCR-kit was purchased from Finnzymes, Finland. Monsanto kindly provided MVP (Mycogen Vegertative Protein) cells containing about $19.5 \%$ Cry1Ac toxin.

\section{Insect Bioassay}

Field strains that survived on Bt cotton served as the initial culture for selection for resistance. F1 progeny were reared on semi synthetic diet (10) incorporated with Cry1Ac, 0.2 ug per well in 12-well ICN-Linbro multiwell trays till pupation. Larvae were transferred onto toxin-incorporated diet, once in two days. The entire assay was performed at a temperature of $27 \pm 1^{\circ} \mathrm{C}$ and $70 \%$ relative humidity. Fourth instar larvae (approx.120mg) were used throughout the experiment.

Isolation of Cry1Ac toxin from Mycogen Vegetative protein cells

MVP powder (100 mg) was suspended in 10 $\mathrm{ml}$ of autoclaved distilled water vortexed for 5 minutes, followed by centrifugation at $9668 \mathrm{~g}$ for 5 minutes at $4^{\circ} \mathrm{C}$. Supernatant was discarded and the pellet obtained was resuspended in $10 \mathrm{ml}$ of lysis buffer $(50 \mathrm{mM}$ Tris buffer, 50mM EDTA and $15 \%$ sucrose, $\mathrm{pH}$ 8.0). MVP- buffer suspension was incubated at room temperature for 3 hours followed by sonication on ice for 3 minutes at $40 \mathrm{~Hz}$. Sonicated suspension was centrifuged at $9668 \mathrm{~g}$ for 20 minutes at $4^{\circ} \mathrm{C}$. Supernatant was discarded and the pellet was dissolved in $10 \mathrm{ml}$ crystal wash-I solution $(0.5 \mathrm{M} \mathrm{NaCl}$, $2 \%$ Triton X-100). Suspension was vortexed gently and incubated on ice for 30 minutes. Samples were centrifuged at $9668 \mathrm{~g}$ for 10 minutes at $4^{\circ} \mathrm{C} .10 \mathrm{ml}$ of crystal wash- II solution $(0.5 \mathrm{M} \mathrm{NaCl})$ was added $(10 \mathrm{ml})$ into the pellet. Suspension was vortexed gently and centrifuged at $9668 \mathrm{~g}$ for 10 minute at $4^{\circ} \mathrm{C}$ and 
supernatant was discarded. The pellet obtained was resuspended in a solution $(1 \mathrm{ml})$ $\begin{array}{llllll}\text { containing } & 8 & \mathrm{M} & \text { urea, } & 0.285 & \mathrm{M}\end{array}$ mercaptoethanol, $0.05 \mathrm{M}$ sodium carbonate, $\mathrm{pH}$ 10.5. The suspension was incubated for 3 hours at room temperature followed by centrifugation at $9,825 \mathrm{~g}$ for 20 minutes at $4^{\circ} \mathrm{C}$ and the pellet was discarded. The supernatant containing Cry1 Ac toin was stored at $-20^{\circ} \mathrm{C}$.

Total RNA isolation from the midgut of susceptible and resistant strains of Helicoverpa armigera to Cry1Ac toxin

Total RNA was isolated from the midgut of late fourth instar larvae of susceptible and resistant Helicoverpa armigera (11) with some modifications. Larvae were reared on diet containing MVP-5000X that served to induce the desired mRNA in sufficient quantity. A single insect about $120 \mathrm{mg}$ was dissected in ice-cold phosphate buffer saline having $1.15 \% \mathrm{KCl}$ and placed in $1.5 \mathrm{ml}$ autoclaved sterile microcentrifuge tube containing $5 \mu \mathrm{l}$ denaturation solution. (4 M guanidium thiocyanate, $25 \mathrm{mM}$ sodium citrate, $0.5 \%$ sodium sarcosinate and $0.1 \mathrm{M} \quad \beta-$ mercaptoethanol).

\section{Reverse Transcription Polymerase Chain} Reaction for amplification of trypsin specific mRNAs

Trypsin specific primers were designed based on the conserved regions of the published insects proteases sequences in NCBI (National Centre for Biotechnological Information) GenBank database (Table 1).

The primers were diluted to $2 \mathrm{pM} / \mu 1$ with autoclaved distilled water. Amplification was carried out for 35 cycles on PTC-100 (Programmable Thermo Controller) of MJ Research Pvt. Ltd., USA. RT-PCR products were loaded on $1.4 \%$ agarose gel for electrophoresis, using Labnet international unit. The products were run with a constant current of $35 \mathrm{~mA}$ for $2.5 \mathrm{~h}$. Gel photographs were digitally recorded using a gel documentation system. DNA fragments (Trypsin specific, $\sim 560 \mathrm{bp}$ ) to be used for sequencing were purified by Sigma Gel Extraction Kit by manufacturers protocol.

Sequencing of the purified fragment of trypsin of susceptible and resistant strains of Helicoverpa armigera to Cry1Ac toxin

A PCR reaction was carried of the purified cDNAs to check the integrity of the single band and to determine the amenability of the reaction to an annealing temperature of $50^{\circ} \mathrm{C}$ used in sequencing. The PCR products were visualized on $1.4 \%$ agarose gel electrophoresis and presence of a single band was ensured. Finally sequencing PCR was carried with the eluted DNA. Sequencing was carried out on CEQ 2000, an 8 capillary system using reagents and methodologies provided in their catalogue.

\section{Sequence analysis}

Sequences were subjected BLASTX program at NCBI GenBank database (www.ncbi.nlm.nih.gov/BLAST) to check the sequence similarity. Sequences showing considerable similarity with the query sequence were downloaded from the public database and aligned using Clastal X 1.8 program (http://www-igbmc.ustrasbg.fr/BioInfo/) (12). Output of aligned file was subjected to phylogenetic analysis using PHYLIP 3.6a (http://evolution.gs.washington.edu/phylip.ht ml) (13). SEQBOOT was used to generate multiple data set using 1000 replicates for further analysis. Since the sequence similarity was high it was subjected to DNAPARS program (14) to create unrooted parsimony tree, which was further subjected to CONSENSE to create consensus out of 1000 
data set replicates. This consensus tree was drawn using program DRAWTREE and labeled accordingly

\section{Results and Discussion}

\section{Insect Bioassay}

One-day-old larvae were released on diet coated with different concentration of Cry1Ac. Mortality were observed from the third day onwards. The mortality at the end of sixth day is subjected to analysis (Table 2). The bioassay result was subjected to Log dose probit analysis and $\mathrm{LD}_{50}$ values were obtained to calculate resistance ratio (Table 3). The resistant strain exhibited III-fold resistance to Cry1Ac compared to a universal susceptible strain.

Partial sequencing of putative trypsin gene in Cry1Ac susceptible and resistant strains of Helicoverpa armigera

RT-PCR with trypsin primers (TT1-15F, TT1576R) yielded a fragment of $560 \mathrm{bp}$, detected on $1.4 \%$ agarose gel electrophoresis. This band was also confirmed after the purification of DNA fragments and before sequencing. Based on the partial sequences of putative trypsin mRNA of Helicoverpa armigera (accession no. AF045138) trypsin specific primers were designed. There was no amino acid change at the catalytic triad of the trypsin specific gene in these both strains $\left(\mathrm{Asp}_{102}\right.$, Ser 195). Asp 189 , which determines the trypsin-like specificity, was present in both the strains. Sequencing demonstrated differences at four amino acid positions in susceptible and resistant strain. Threonine, aspartic acid, serine and histidine at 180, 185, 186 and 192 amino acid positions in susceptible strain were substituted with alanine, valine, glycine and glutamic acid respectively in resistant strain (Fig.2). The specificity determining residues (glycine 216) was present in resistant strain while this region was not sequenced in susceptible strain.

The phylogenic tree represents above $99 \%$ similarity between the susceptible and resistant strain used in this study. This similarity was compared with trypsin cDNAs of other insects. Group B represents about 95\% similarity in sequences with the two strains while group A indicates about $97 \%$ similarity in sequences (Fig.2).

Trypsins are abundant in lepidopteran insect gut. Protease mediated resistance to $\mathrm{Bt}$ in some insects is related to with the decreased activity of major serine proteases such as trypsin (15). Zhu et al., (15) compared cDNA sequences, mRNA expression levels, and genomic DNA for chymotrypsin-like enzymes in Bt-susceptible and resistant strains of Plodia interpunctella. They suggested that chymoyrpsin-like protase genes and their transcription were similar in the Bt-susceptible and Bt-resistant strains of Plodia interpunctella. All the trypsin-like cDNAs contain the catalytic triad $\mathrm{His}_{57}, \mathrm{Asp}_{102}$ and $\mathrm{Ser}_{195}$ in their amino acid sequences (9). $\mathrm{Asp}_{189}$ residue determines the trypsin-like specificity for basic amino acids. The primary objective of sequencing of trypsin-specific gene was to detect any change of nucleotide in catalytic site Asp 102 and Ser $_{195}$. His 57 , which is a part of catalytic triad, could not covered in sequencing.

Table.1 Trypsin specific primers

\begin{tabular}{|c|c|c|c|}
\hline Primer Name & Primer Sequence & F/R & Product \\
\hline TT1_15F & CTTTGATGGATTCTTATTCG & F & 562 bp \\
\hline TT1_576R & GATGATCCAGTTGGTGTAAG & R & \\
\hline
\end{tabular}


Fig.1 Comparison of Putative Trypsin of Cry1Ac susceptible and resistant Helicoverpa armigera with published insect Trypsin sequences

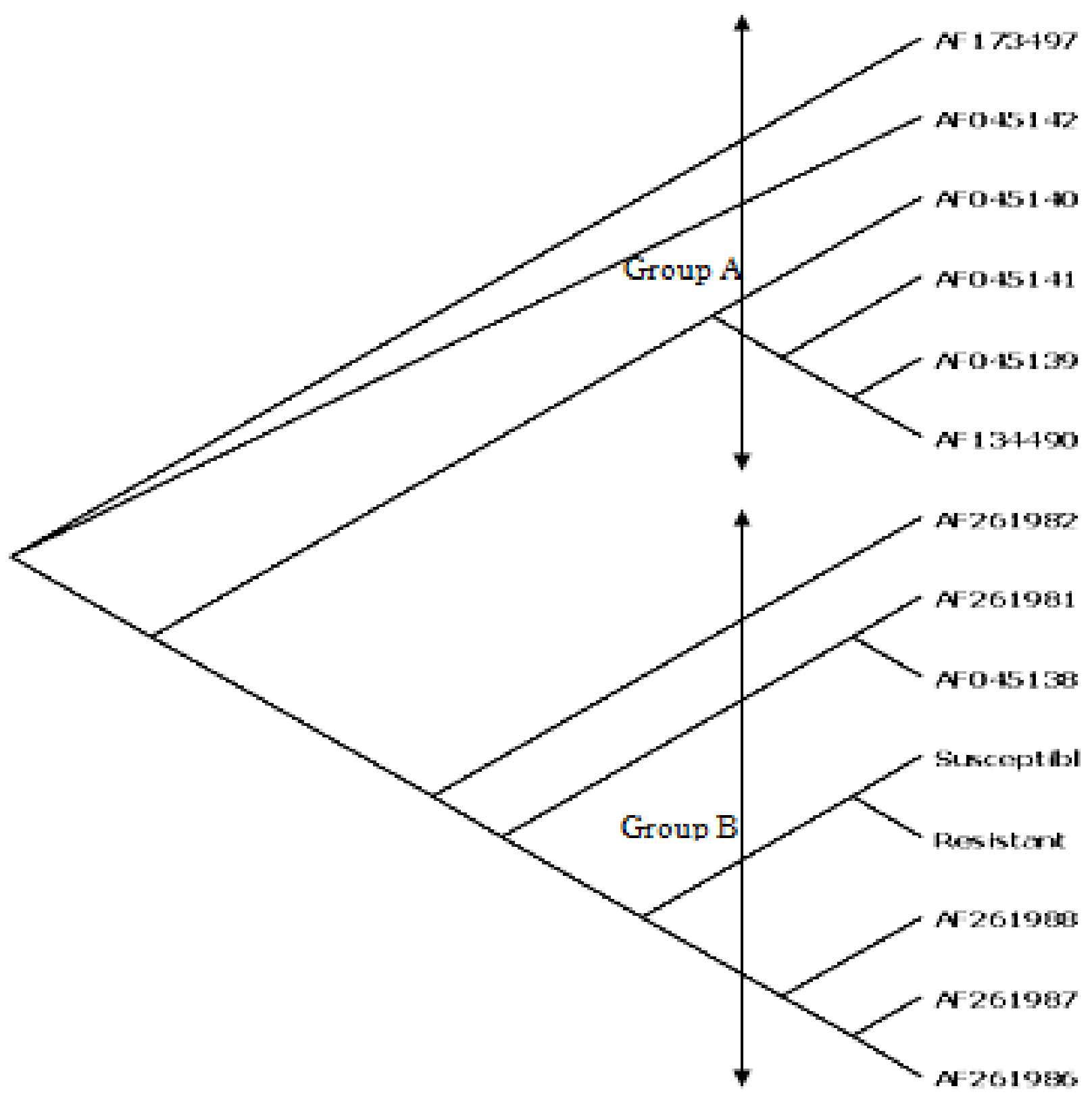


Fig.2
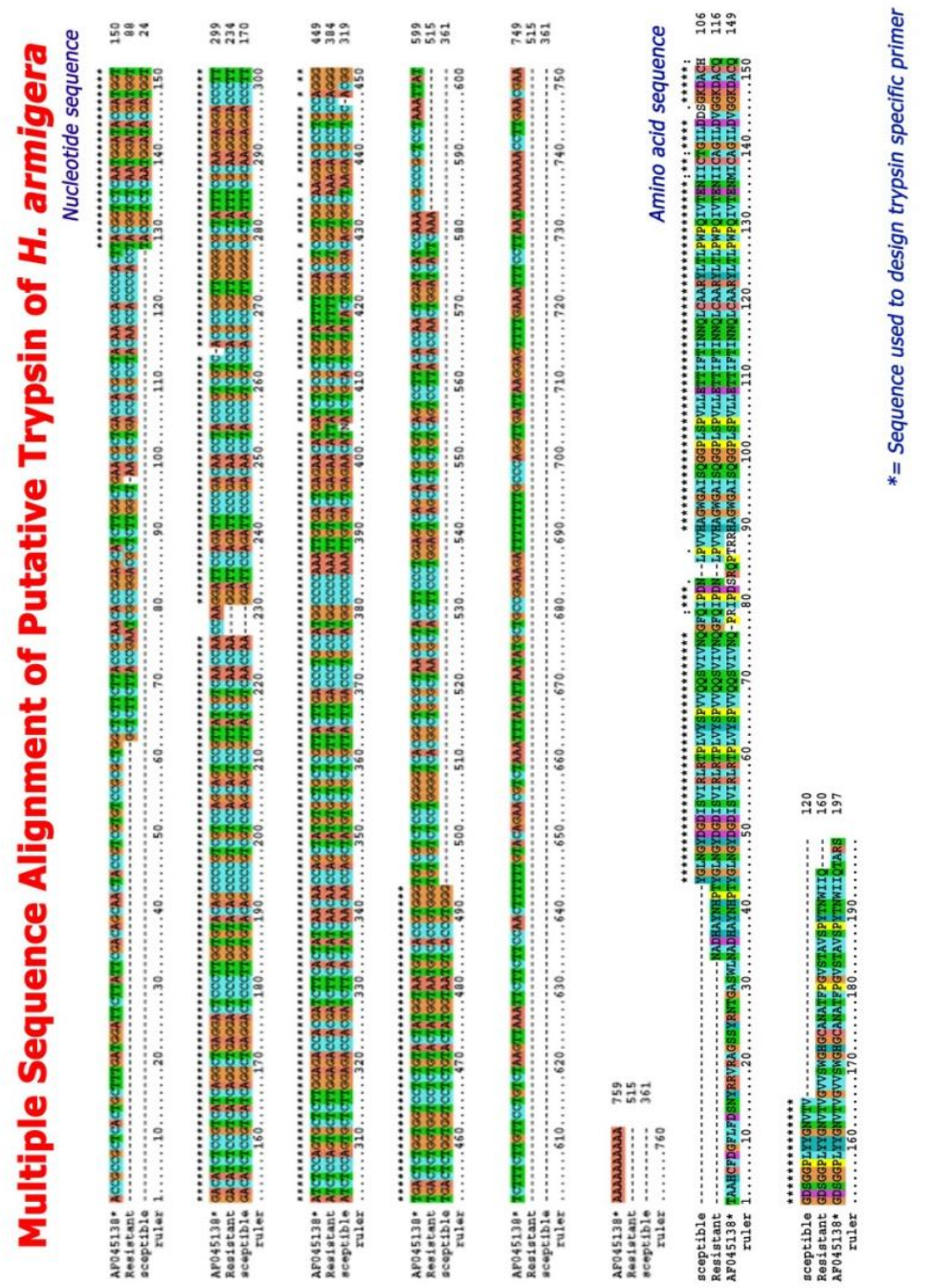

Although the study indicated amino acid differences in susceptible and resistant strain, the changes cannot be correlated with the resistance mechanism of insects to Cry1Ac toxin.

\section{References}

Gill, S. S., Cowles, E. A., Pietrantonio, P. V., 1992., "The mode of action of Bacillus thuringiensis endotoxins," Annu. Rev. Entomol., 37, pp. 615-636.

Oppert, B., Kramer, K. J., Johnson, D. E., MacIntosh, S. C., McGaughey, W. H., 1994, "Altered protoxin activation by

midgut enzymes from a Bacillus thuringiensis resistant strain of Plodia interpunctella," Biochem. Biophy. Res. Comm., 198, pp. 940-947.

Oppert, B., Kramer, K. J., Johnson, D., Upton, S. J., McGaughey, W. H., 1996, "Luminal proteases from Plodia interpunctella and the hydrolysis of Bacillus thuringiensis CryIA(c) protoxin," Insect Biochem. Molec. Biol., 26, pp. 571-583.

Oppert, B., Kramer, K. J., Beeman, R. W., Johnson, D., McGaughey, W. H., 1997, "Protease-mediated insect resistance to Bacillus thuringiensis toxins," J. Biol. Chem., 272, pp. 23473-23476. 
Forcada, C., Alcacer, E., Garcera, M. D., Martýnez, R., 1996, "Differences in the midgut proteolytic activity of two Heliothis virescens strains, one susceptible and one resistant to Bacillus thuringiensis toxins," Arch. Insect Biochem. Physiol., 31, pp. 257-272.

Manjunath, T. M., Bhatnagar, V. S., Pawar, C. S., Sithanantham, S., 1989, "Economic importance of Heliothis species in India and an assessment of their natural enemies and host plants." Proce. the international workshop on Biological Control of Heliothis, New Delhi, India, pp. 197-228.

Kranthi, K. R., Jadhav D. R., Wanjari R. R., Shakir Ali, S., Rusell, D., 2001, "Carbamate and organophosphate resistance in cotton pests in India, 1995 to 1999," Bulletins of Entomological Research, 91, pp. 37-46.

Tojo, A., Aizawa K., 1983, "Dissolution and degradation of Bacillus thuringiensis $\delta$ endotoxin by gut juice proteases of the silkworm Bombyx mori," Appl. Environ. Microbiol., 45, pp.576-580.

Bown, D. P., Wilkinson, H. S., Gatehouse, J. A., 1997, "Differentially Regulated InhibitorSensitive and Insensitive Protease Genes from the Phytophagous Insect Pest, Helicoverpa armigera, are Members of Complex Multigene Families," Insect Biochem. Molec. Biol., 27, pp. 625-638.

Armes, N. J., Jadav, D. R., Lonergn, P. A., 1994, "Insecticide resistance in Helicoverpa armigera (Hubner): status and prospectus for its management in India," Proc. of the World Cotton Research Conference-1, G. A. Constable and N. W.
Forresrer, Eds., Brisbane, Australia, pp. 552-533.

Strommer, J., Gregerson, R., Vayda, M., 1993, "Isolation of Characterization of Plant mRNA," In: Glick B. R. and Thompson J. E., Eds., Methods in Plant Molecular Biology and Biotechnology, CRC press, Florida, pp. 49-65.

Thompson, J. D., Gibson, T. J., Plewniak, F., Jeanmougin, F., Higgins, D. G., 1997, "The ClustalX windows interface: flexible strategies for multiple sequence alignment aided by quality analysis tools," Nucleic Acids Research, 24, pp. 4876-4882.

Felsenstein, J., 2002, "PHYLIP (Phylogeny Inference Package) version 3.6a3," Distributed by the author, Department of Genome Sciences, University of Washington, Seattle.

Fitch, W. M., 1975, "Toward finding the tree of maximum parsimony," Proc. of the Eighth International Conference on Numerical Taxonomy, G. F. Estabrook. W. H. Freeman, ed., San Francisco. pp. 189-230.

Huang, F., Zhu, K. Y., Buschman, L. L., Higgins, R. A., Oppert, B., 1999, "Comparison of midgut proteases in Bacillus thuringiensis-susceptible and resistant European corn borer, Ostrinia nubilalis (Lepidoptera: Pyralidae)," Pestic. Biochem. Physiol., 65, pp.132-139.

Zhu, Y. C., Oppert, B., Kramer, K. J., McGaughey, W. H., Dowdy, A. K., 1997, "cDNAs for a chymotrypsin-like protein from two strains of Plodia interpunctella," Insect Biochemistry and Molecular Biology., 27, pp.1027-1037.

\section{How to cite this article:}

Sharma, K. M., A. A. Bharose and Dhawale, R. N. 2021. Partial Sequencing of Putative Trypsin cDNAs in Cry1Ac Susceptible and Resistant Strains of Helicoverpa armigera (Hubner). Int.J.Curr.Microbiol.App.Sci. 10(05): 79-85. doi: https://doi.org/10.20546/ijcmas.2021.1005.012 